\title{
Effects of a Health Education Program on Water Treatment and Safe Storage, East Nile Locality, Khartoum State
}

\author{
Mawahib Mohammed Salih Ibrahim ${ }^{1 *}$, Ahmed Sayed Ahmed ElSayed ${ }^{2}$, Fatima Fadul Ali Osman ${ }^{3}$ \\ ${ }^{1}$ MSc in Community Health Nursing, Department of Nursing, Faculty of Medical Technical Sciences, Alzaiem Alazhari University, \\ Khartoum, Sudan \\ ${ }^{2}$ Professor Department of Surgery, Department of Surgery, Faculty of Medicine, Alzaiem Alazhari University, Khartoum, Sudan \\ ${ }^{3}$ Professor Department of Health Education, Department of Health Education, Faculty of Public Health, Alzaiem Alazhari University, \\ Khartoum, Sudan
}

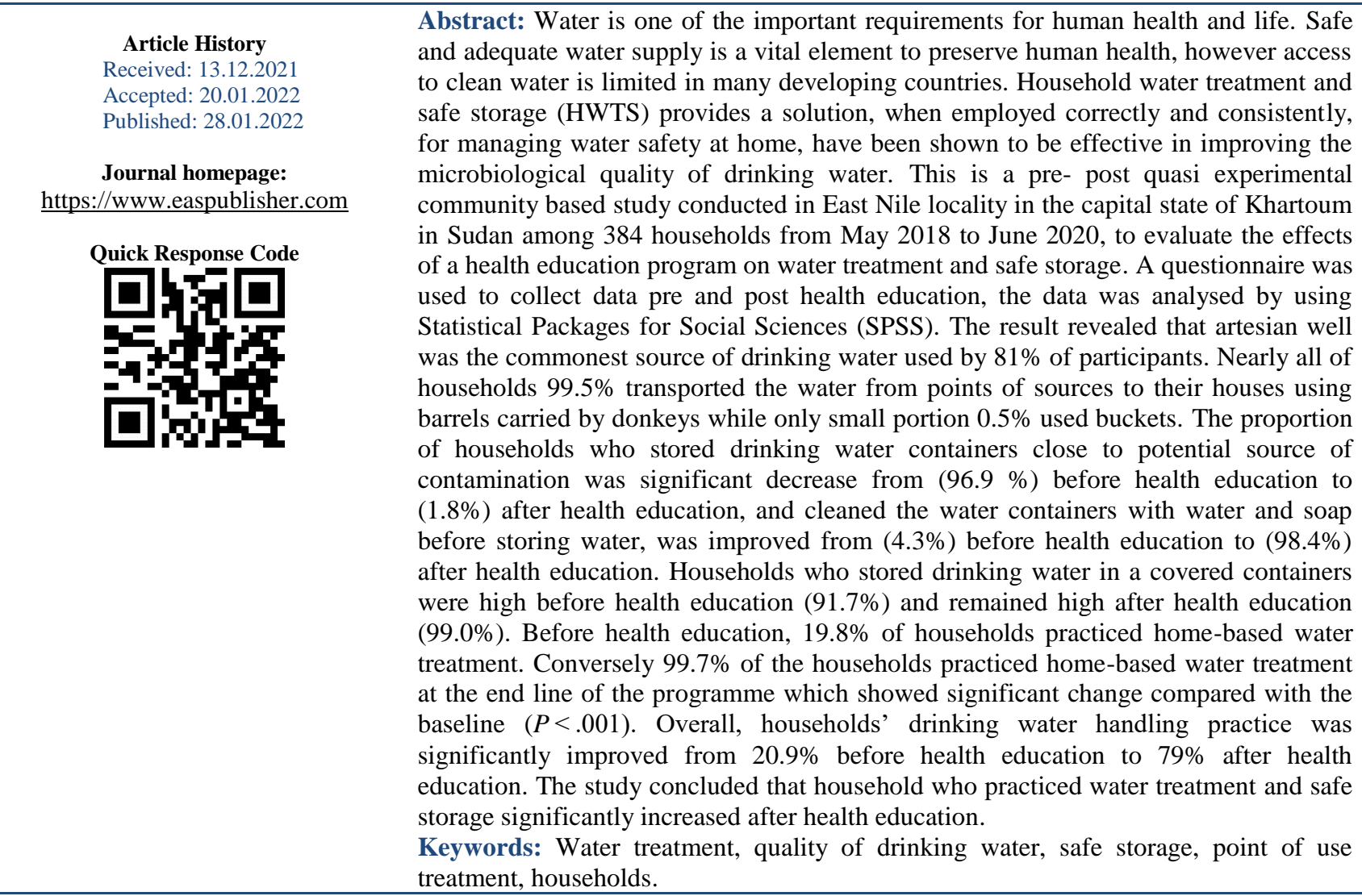

Copyright (C) 2022 The Author(s): This is an open-access article distributed under the terms of the Creative Commons Attribution 4.0 International License (CC BY-NC 4.0) which permits unrestricted use, distribution, and reproduction in any medium for non-commercial use provided the original author and source are credited.

\section{INTRODUCTION}

Water is essential to sustain life, and a satisfactory (adequate, safe and accessible) supply must be available to all. Improving access to safe drinking water can result in tangible benefits to health (WHO, 2011). Consumption of clean water is necessary for human health all over the world. Since water is a universal solvent, it is a major source of infections. According to World Health Organization (WHO) $80 \%$ of diseases are water borne. Drinking water in various countries does not meet WHO standards (Khan et al., 2013) and still grappling with challenges related to water access with 663 million people in the world estimated to lack access to improved water supplies, half of whom are in Sub-Saharan Africa (WHO, 2015). About $3.1 \%$ deaths occur due to the unhygienic and poor quality of water (Pawari and Gawande, 2015).

*Corresponding Author: Mawahib Mohammed Salih Ibrahim

MSc in Community Health Nursing, Department of Nursing, Faculty of Medical Technical Sciences, Alzaiem Alazhari University, Khartoum, Sudan 
Treating water and safely storing it in the home are commonly referred to as "household water treatment and safe storage" (HWTS) or treating water at the "point of use". Although HWTS is not new, its recognition as a key strategy for improving public health is just emerging. For centuries, households have used a variety of methods for improving the appearance and taste of drinking water (WHO, 2013).

Household water treatment and safe storage (HWTS), such as boiling, filtering, or chlorinating water at home, have been shown to be effective in improving the microbiological quality of drinking water. However, estimates of their protective effect against diarrhea, a major killer, have varied widely (Clasen, 2015).

Safe water chain includes all processes involved in ensuring that water is not contaminated through all stages from water source to consumption. Key stages in the safe water chain include water collection, handling, transportation, storage and treatment. Although interventions focused on improving water storage or treatment have registered positive out comes in terms of diseases reduction (SSemugabo, 2019).

In Sudan Water in the household either tends to be stored in plastic containers, in ceramic Zeer or in tanks, including underground tanks constructed of bricks and cement. For Zeer a shared cup is often utilised that is dipped into the container. Water treatment used boiling sedimentation including in Zeer and use of local materials such as alluvial (clay) in the north, groundnut, Moringa (and possibly Neem) trees, Nana plant / Mint, Cardamom, oil put on top of the water after boiling, lemon and putting in sunlight for a few hours ( Ministry of Water Resources, 2017).

\section{Materials and Methods}

This is a pre- post quasi experimental community based study conducted from May 2018 to June 2020, among selected villages in a rural area in East Nile Locality in Khartoum State, Sudan.

Khartoum State is one of the 18 states of Sudan. It is the most populous and contains the capital city and by extension as in all developing countries the majority of the country's infrastructure.

East Nile (Sharg Elneel) locality is located in the south east part of Khartoum State and is one of the seven localities comprising Khartoum State, it is bordered to the north by River Nile State, from the south the eastern side of Aljazeera State, the east is bounded by the States of Kassala and Gedaref and to the west it is bounded by Khartoum Bahary locality and the Blue Nile River. It is administratively divided into in eight administrative units: two of them considered as urban (SharqAlneel and Alhaj-Yousif) and the other six are rural (Alalafoon, Umdawanban, Alasailat, Wadi Suba, Wad Abu-Salih, and Abu-Dlaig). So the majority of the populations are poor rural individuals.

Four villages were selected from Wad $\mathrm{Abu}$ Salih administrative units for the study (AlfareeAlahamdah- Wad Shion- Eid Allnis).

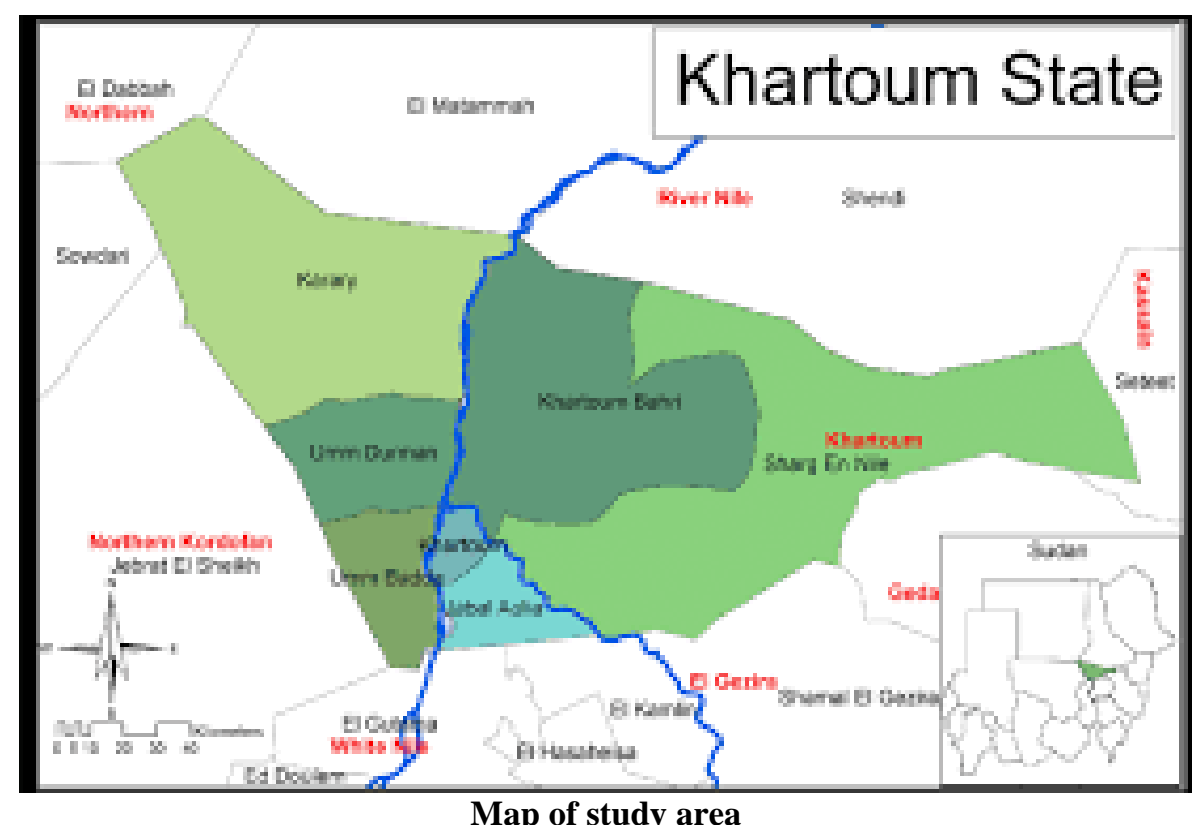

Map of study area

The inclusion criteria were both adult males and females, who live in the four villages and agreed to be the part of the study. The exclusion criteria were people living outside these four villages, people who disagreed to be the part of the study and children. The sample size was determined by ready table for measuring sample size (Glenn D.Israel, 2013), where confidence level $=95 \%$ and $\mathrm{P}=0.5$,so as the total 
Mawahib Mohammed Salih Ibrahim et al., EAS J Nurs Midwifery; Vol-4, Iss-1 (Jan-Feb -2022): 8-15

number of population for the four selected villages was 6697, taken from health survey Ministry of healthKhartoum State, Administration of Primary Health Care, East Nile Locality (2018-2019). According to the table the sample size was 384 participants, who were then selected by a random sample technique from April to June 2019 , through a house to house survey by the health care providers. The houses in the village were visited and during the visit their practices regarding procurement, storage and consumption of water were observed by the interviewer. The data collection tool was a questionnaire prepared by the researcher, consisting of closed and open questions with different contents such as socio-demographic characteristics, water facilities and water treatment and storage practices. Data consistency was checked and exported to Statistical Package for the Social Sciences (SPSS) for the analysis.

\section{Ethical Approval}

Was obtained from the Institutional Review Boards of::Alzaiem Alazhari University, Ministry of health- Khartoum State-Administration of health promotion- East Nile Locality- Administration of Primary Health Care and the local community leaders. After all these were prepared verbal consent was obtained from each subject who agreed to be part of the study, confidentiality of information was maintained and explained to the participants.

\section{RESULTS}

A total of 384 households were including in the study. The majority of participant's ages were between 31 to 40 years. Half of them $(51.8 \%)$ were illiterate and more than half of the participants $(62.5 \%)$ were of moderate socioeconomic class with the head of the household earning 2.001 - 3.000 S.P (Sudanese Ponds) per month (Table 1).

Table 1: Socio-demographic characteristic of the participants $(n=384)$

\begin{tabular}{|c|c|c|}
\hline Socio-demographic characteristic of the participants & Frequency & Percent \\
\hline \multicolumn{3}{|l|}{ Age } \\
\hline 21 to 30 years & 11 & 2.9 \\
\hline 31 to 40 years & 278 & 72.4 \\
\hline Above 40 years & 95 & 24.7 \\
\hline Total & 384 & 100.0 \\
\hline \multicolumn{3}{|l|}{ Level of education of study participants } \\
\hline Illiterate & 199 & 51.8 \\
\hline Khalwa & 12 & 3.1 \\
\hline Primary & 163 & 42.4 \\
\hline Secondary & 9 & 2.3 \\
\hline University & 1 & .3 \\
\hline Total & 384 & 100.0 \\
\hline \multicolumn{3}{|l|}{ Households income every month } \\
\hline 1,000 and less & 5 & 1.3 \\
\hline $1,001-2,000$ & 131 & 34.1 \\
\hline $2,001-3,000$ & 240 & 62.5 \\
\hline More than 3,000 & 8 & 2.1 \\
\hline Total & 384 & 100.0 \\
\hline
\end{tabular}

The main source of drinking water in the study area was artesian wells (Figure 1) used by $81 \%$ of the respondents while $19 \%$ obtained their water from rain water collection (hafir).

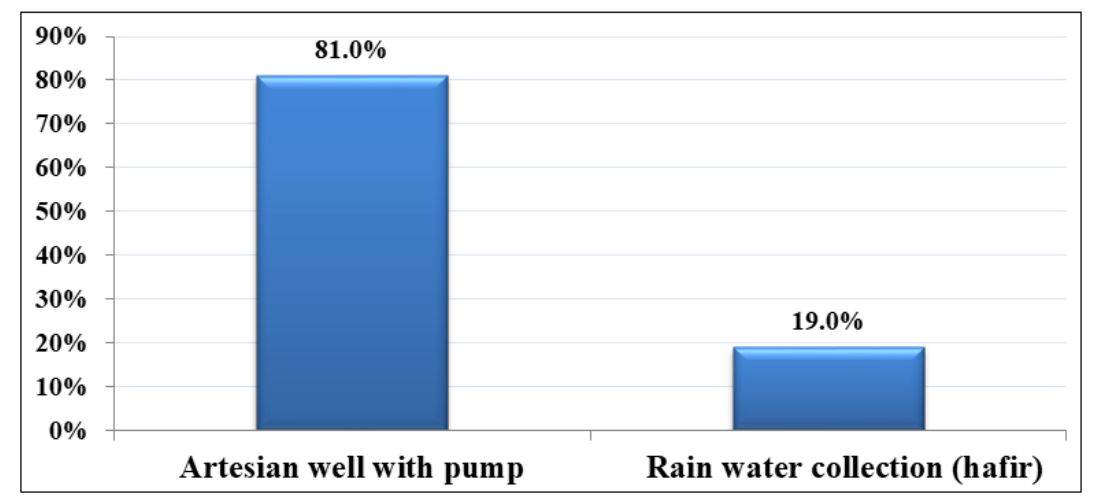

Figure 1: Sources of drinking water 
Mawahib Mohammed Salih Ibrahim et al., EAS J Nurs Midwifery; Vol-4, Iss-1 (Jan-Feb -2022): 8-15

Nearly all of the households (99.5\%) transported the water from the sources to their houses using barrels carried by donkeys while only $(0.5 \%)$ used buckets (Figure 2).

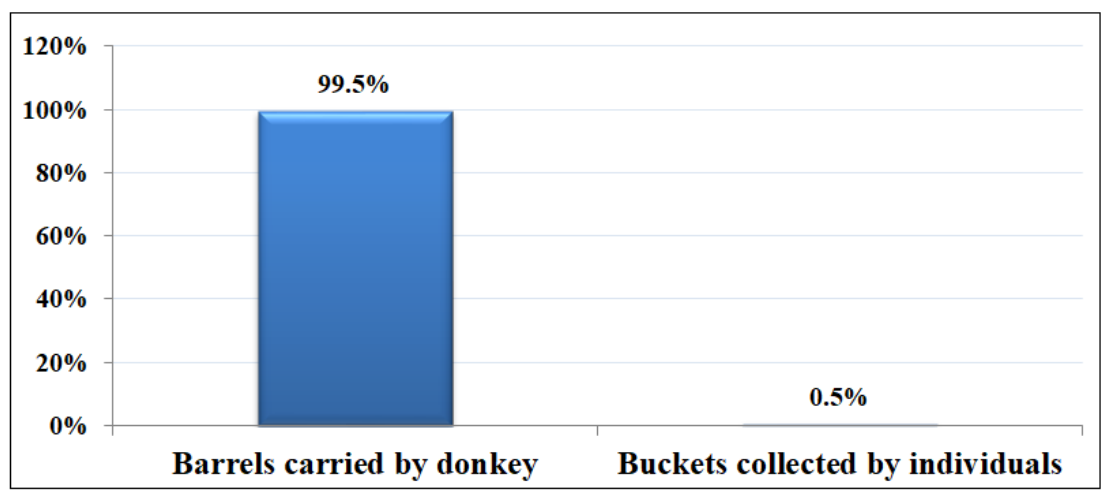

Figure 2: Water transport from point of source to the house

Regarding the drinking water containers close to potential source of contamination was significant decrease from $(96.9 \%)$ before health education to $(1.8 \%)$ after health education, $\mathrm{P}$. value 0.00 (Table 2 ).

Table 2: Drinking water containers close to potential source of contamination before and after health education

\begin{tabular}{|c|c|c|}
\hline Drinking water containers closed to potential source of contamination & Before & After \\
\hline Yes & $\begin{array}{l}372 \\
(96.9 \%)\end{array}$ & $\begin{array}{l}7 \\
(1.8 \%)\end{array}$ \\
\hline No & $\begin{array}{l}12 \\
(3.1 \%)\end{array}$ & $\begin{array}{l}377 \\
(98.2 \%)\end{array}$ \\
\hline Total & $\begin{array}{l}384 \\
(100 \%)\end{array}$ & $\begin{array}{l}384 \\
(100 \%)\end{array}$ \\
\hline Pvalue & \multicolumn{2}{|l|}{$\mathbf{0 . 0 0 0}$} \\
\hline
\end{tabular}

Concerning covered water containers at home level. Households who stored drinking water in a covered containers was high before health education
$(91.7 \%)$ and remain high after health education $(99.0 \%)$ (Table 3).

Table 3: Drinking water stored in a covered container, before and after health education

\begin{tabular}{|l|l|l|}
\hline Drinking water stored in a covered container & Before & After \\
\hline Yes & 352 & 380 \\
& $(91.7 \%)$ & $(99.0 \%)$ \\
\hline No & 32 & 4 \\
Total & $(8.3 \%)$ & $(1.0 \%)$ \\
& 384 & 384 \\
\hline P value & $(100 \%)$ & $(100 \%)$ \\
\hline
\end{tabular}

Significant difference between storage vessels used for drinking water at home, before health education used storage barrels (100.0) changed to
(97.4\%) clay pots (Alzeer) after health education, P. value 0.00 (Table 4$)$.

Table 4: Storage vessels used for drinking water at home, before and after health education

\begin{tabular}{|l|l|l|}
\hline Storage vessels used for drinking water at home & Before & After \\
\hline Storage barrels & 384 & 9 \\
& $(100 \%)$ & $(2.3 \%)$ \\
\hline Storage buckets & 0 & 1 \\
& $(0 \%)$ & $(0.3 \%)$ \\
\hline Open tanks & 0 & 0 \\
& $(0 \%)$ & $(0 \%)$ \\
\hline Clay pots (Alzeer) & 0 & 374 \\
& $(0 \%)$ & $(97.4 \%)$ \\
\hline Total & 384 & 384 \\
& $(100 \%)$ & $(100 \%)$ \\
\hline P value & $\mathbf{0 . 0 0 0}$ & \\
\hline
\end{tabular}


Regarding the container cleaned with water and soap before storing water, the result found that it was significantly improved from $(4.3 \%)$ before health education to $(98.4 \%)$ after health education, P. value 0.00 (Table 5).

Table 5: Container cleaned with water and soap, before storing water, before and after health education

\begin{tabular}{|l|l|l|}
\hline Container cleaned with water and soap before storing water & Before & After \\
\hline Yes & 13 & 378 \\
& $(3.4 \%)$ & $(98.4 \%)$ \\
\hline No & 371 & 6 \\
& $(96.6 \%)$ & $(1.6 \%)$ \\
\hline Total & 384 & 384 \\
& $(100 \%)$ & $(100 \%)$ \\
\hline$P$ value & $\mathbf{0 . 0 0 0}$ & \\
\hline
\end{tabular}

Practice of home - based water treatment to make it safe to drink was significant improved (P. value
$0.00)$ form $(2.9 \%)$ before health education to $(99.7 \%)$ after health education (Table 6).

Table 6: Participants who treat water in any way to make it safer to drink, before and after health education

\begin{tabular}{|l|l|l|}
\hline Participants who treat water in any way to make it safer to drink & Before & After \\
\hline Yes & 76 & 383 \\
& $(19.8 \%)$ & $(99.7 \%)$ \\
\hline No & 308 & 1 \\
& $(80.2 \%)$ & $(0.3 \%)$ \\
\hline Total & 384 & 384 \\
& $(100 \%)$ & $(100 \%)$ \\
\hline P value & $\mathbf{0 . 0 0 0}$ \\
\hline
\end{tabular}

Concerning techniques used to treat water before health education included strain it through a cloth $(16.4 \%)$, let it to sediment and settle $(2.9 \%)$, $(0.3 \%)$ for boiling and exposure to sun light in closed container for $6 \mathrm{hr}$, changed to $(98.9 \%)$ boiling, $(0.8 \%)$ strain it through a cloth and $(0.3 \%)$ let it to sediment and settle after health education, $\mathrm{P}$. value 0.00 it was significant (Table 7).

Table 7: What participants do to the water to make it safer to drink, before and after health education

\begin{tabular}{|l|l|l|}
\hline What participants do to the water to make it safer to drink & Before & After \\
\hline Boiling & 1 & 380 \\
& $(0.3 \%)$ & $(98.9 \%)$ \\
\hline Strain it through a cloth & 63 & 3 \\
& $(16.4 \%)$ & $(0.8 \%)$ \\
\hline Use water filter (ceramic, sand, etc.) & 0 & 0 \\
& $(0 \%)$ & $(0 \%)$ \\
\hline Let it to sediment and settle & 11 & 1 \\
& $(2.9 \%)$ & $(0.3 \%)$ \\
\hline Exposure to sun light in closed container for 6 hr & 1 & 0 \\
& $(0.3 \%)$ & $(0 \%)$ \\
\hline Total & 76 & 384 \\
& $(100 \%)$ & $(100 \%)$ \\
\hline P value & $\mathbf{0 . 0 0 0}$ & \\
\hline
\end{tabular}

\section{DISCUSSION}

Safe and adequate water supply is a vital element to preserve human health; however, access to clean water is limited in many developing countries.

Efforts to improve and maintain the quality of stored water in the home have included the development of many safe water storage and point of use water treatment technologies, several of which have been shown to be effective for reducing contamination.
This is a pre- post quasi experimental community based study aimed to evaluate the effect of a health education program on water treatment and safe storage. The majority of participants ages were between 31 to 40 years. More than half of the participants $(62.5 \%)$ belonged to the moderate socioeconomic class with the head of the household month (Table 1).

In the current study illiteracy rate among participants was $(51.8 \%)$, this result is consistent with a community based cross-sectional study in rural setting 
of North Gondar Zone, Ethiopia (Getachew et al., 2018) where $58.6 \%$ was the level of illiteracy rate.

The main sources of drinking water in the study area was artesian well used by $(81 \%)$ of the respondents while $(19 \%)$ obtained their water from rain water collection (hafir) which is considered as not safe for drinking (Figure 1).

Regarding transportation of drinking water from the source to the homes. Our study findings showed that nearly all of households $99.5 \%$, transported the water from points of sources to their houses using barrels carried by donkeys while only small portion. $5 \%$ used buckets (Figure 2). This finding disagreed with study done by (Pradhan et al., 2017) in field practice, India, where buckets (54\%), steel container (22.8\%), and pipes $(23.2 \%)$ were used as transport vessels.

Location of drinking water storage containers away from the source of contamination is considered one of the best ways to protect drinking water from contaminants, by storing containers in a cool dry place away from direct sun light. In the present study households who kept their drinking water storage containers close to sources of contamination was significantly reduced P-value (0.00) after health education (Table 2), our finding corroborated findings from a quasi-experimental study in Rural Southern, India by (Francis et al., 2016), to evaluate the effectiveness of decentralized membrane filtration in village with safe storage in village 1 , without safe storage in village 2 , versus no intervention in village 3 , consisting of central chlorination as per government guidelines, in improving the microbiological quality of drinking water. The result found that placing of storage of drinking water containers away from contamination was increased in the three selected village, although not statistically significant p-value (0.246).

Drinking water from an open container, the water left over night or for a long period of time in an open containers lead to numerous bacteria and is not safe for drinking. Contamination can occur if the water containers are not fully covered. In our study households who stored water in a covered container was high before health education and remained high after health education P-value (0.00), (Table 3) perhaps this good practice is derived from the Sudanese habit and culture to cover utensils to save food and drink, this finding was supported with a matched case-control study by (Mattioli et al., 2014) using data collected from 223 households in Tanzania, to evaluate the relationship between cases of diarrhoea in children under five and the presence of molecular markers of enteric pathogens on hands of mothers and in household stored water. The result revealed that a larger percentage of control households had their stored drinking water covered ( $98 \%$ versus $89 \%, p<0.01)$.
Key factors in the provision of safe household water include the condition and practices of water collection and storage containers or vessels. Drinking water storage containers varied widely in capacity and type. Water must be stored in different container, from the one used to collect or transport it. For storage, containers with a narrow opening are best.

In the present study most of households used clay pots (Alzeer) as storage vessels for drinking water after health education compared with storage barrels before health education, (Table 4) this differences is due to the knowledge acquired during health education sessions regarding benefits of clay pots such as help to keep water cool, improve metabolism, free from all harmful chemical that are found in the plastic containers and better taste, this finding disagrees with a community-based cluster randomized controlled trial study in Jigjiga District, Eastern Ethiopia by (Hashi et al., 2017) to evaluate the effect of hand washing with soap and water, sanitation and hygiene (WASH) educational intervention on the incidence of under five children diarrhoea. The result found that most of the intervention household used jerry cans while quarters of them used pots as storage vessels for drinking water at home.

The practice of washing water storage containers, especially with soap and water helps prevent formation of a slimy layer and build-up of a biofilm inside the storage containers. Cleaning drinking water storage containers is an important component of providing safe and clean drinking water to consumers. In the current study the proportion of households who practiced cleaning the containers with water and soap before storing water was signifanctly improved after health education (Table 5), explanation of the improvement of cleaning containers after health education was due to the knowledge acquired during health education sessions, in addition to confirming applying the practice during home visits, this finding contrast with a randomized study done by (Hamoudi et al., 2012), in rural Andhra Pradesh, India, to evaluate the effect of information provision on treatment households, these latter result revealed a high proportion of households in the control group cleaned their storage vessels and remained high in the treatment group, it was no significant differences $(P<.01)$.

Although HWTS is not new, its recognition as a key strategy for improving public health is just emerging. For centuries, households have used a variety of methods for improving the appearance and taste of drinking-water. Our study revealed that participants who treat water in any way to make it safer to drink was significantly increased after health education ( $\mathrm{p}$ - value 0.00), (Table 6). This finding is in line with an uncontrolled before-and-after intervention study by (Gizaw et al., 2018) in rural Dembiya, northwest Ethiopia, to assess the impacts of the intervention on 
households WASH conditions and prevalence of intestinal parasitic infections, the study concluded that he proportion of households who practiced home-based water treatment was significantly increased at the end line compared with baseline $(p<0.001)$.

Household water treatment applications are any of a range of technologies, devices or methods employed for the purposes of treating water at the household level. The present results reflect that majority of households after health education boiled water to make it safer to drink, while a small portion strained it through a cloth, compared with less than a quarter of households before health education used to strain it through a cloth and small percentage boiled water (Table 7). This changes of methods of treating water was due to the knowledge acquired during the health education session, that the heat removes or inactivates microbial pathogens of water. Add to that the implementation of boiling at household's level consequently every home visits by health care providers showed that they practiced this. This finding disagree with (Musoke et al., 2018) study, who implemented a 3 year wash project in two slums communities in Uganda among 300 households, focusing on safe drinking water and improvement of sanitation. The project implemented community and school interventions in addition to capacity building initiatives, it revealed that more households in the base line and end boiled their water.

\section{CONCLUSION}

The proportion of households who stored drinking water in clean area, covered drinking water storage containers, cleaned the water containers before storing water and washed their hands before handling water was improved after the health education program. Also households practicing home-based water treatment was increased at the end of the program, as a significant proportion of households practiced good drinking water handling after the health education program compared with before the health education.

\section{RECOMMENDATIONS}

Awareness programs through rigorous, frequent and effective implementation of well-designed health education programs with the full and active participation of Ministry of health, organizations working on safe water programs and different partners at the community level to promote safe drinking water handling practices and water quality should be continusly applied across the study area.

Such programs are crucial to prevent contamination across the villages, to improve the status of public health and also to reduce diarrhoeal morbidity. Quality assessment of the water source should be conducted regularly to assure that safe drinking water with national quality standards is available to everyone.
Finally ideally a safe water network should be established in all villages.

\section{REFERENCES}

- Clasen, T. (2015). Household water treatment and safe storage to prevent diarrheal disease in developing countries. Current environmental health reports, 2(1), 69-74.

- Francis, M. R., Sarkar, R., Roy, S., Jaffar, S., Mohan, V. R., Kang, G., \& Balraj, V. (2016). Effectiveness of membrane filtration to improve drinking water: A quasi-experimental study from rural Southern India. The American journal of tropical medicine and hygiene, 95(5), 1192-1200.

- Getachew, A., Tadie, A., Chercos, D. H., \& Guadu, T. (2018). Level of faecal coliform contamination of drinking water sources and its associated risk factors in rural settings of north Gondar Zone, Ethiopia: a cross-sectional community based study. Ethiopian journal of health sciences, 28(2), 227-234.

- Gizaw, Z., Addisu, A., \& Dagne, H. (2018). Effects of water, sanitation and hygiene (WASH) education on childhood intestinal parasitic infections in rural Dembiya, northwest Ethiopia: an uncontrolled before-and-after intervention study. Environmental Health and Preventive Medicine, 24(1), 16.

- Glenn, D. I. (2013). Determining Sample Size. Third edition. Gainesville. University of Florida. Cooperative Extension Service, Institute of Food and Agriculture Science, 3.

- Hamoudi, A., Jeuland, M., Lombardo, S., Patil, S., Pattanayak, S. K., \& Rai, S. (2012). The effect of water quality testing on household behavior: evidence from an experiment in rural India. The American journal of tropical medicine and hygiene, 87(1), 18-22.

- Hashi, A., Kumie, A., \& Gasana, J. (2017). Hand washing with soap and WASH educational intervention reduces under-five childhood diarrhoea incidence in Jigjiga District, Eastern Ethiopia: a community-based cluster randomized controlled trial. Preventive medicine reports, 6 , 361-368.

- $\quad$ Khan, N., Hussain, S. T., Saboor, A., Jamila, N., \& Kim, K. S. (2013). Physicochemical investigation of the drinking water sources from Mardan, Khyber Pakhtunkhwa, Pakistan. International journal of physical sciences, 8(33), 1661-1671.

- Mattioli, M. C., Boehm, A. B., Davis, J., Harris, A. R., Mrisho, M., \& Pickering, A. J. (2014). Enteric pathogens in stored drinking water and on caregiver's hands in Tanzanian households with and without reported cases of child diarrhea. PloS one, 9(1), e84939.

- Ministry of Water Resources, Irrigation and Electricity, Federal Ministry of Health. Sudan Drinking Water Safety Strategic Framework. 2017. 
Page 34-35.

https://www.humanitarianresponse.info/sites/www. humanitarianresponse.info/files/2019/07/SudanDrinking-Water-Safety--Strategic-Framework-\%28SDWSSF\%29-2017.PDF

- Musoke, D., Ndejjo, R., Halage, A. A., Kasasa, S., Ssempebwa, J. C., \& Carpenter, D. O. (2018). Drinking water supply, sanitation, and hygiene promotion interventions in two slum communities in Central Uganda. Journal of environmental and public health, 2018, (5), 1-9.

- Pawari, M. J. G. (2015). Ground Water Pollution \& its Consequence. International Journal of Engineering Research and General Science, 3(4), 773-776.

http://pnrsolution.org/Datacenter/Vol3/Issue4/101. pdf

- Pradhan, S. K., Sinha, U., Satapathy, D. M., Swain, A. P., \& Mishra, R. P. (2018). Assessment of household water treatment and storage practices. International Journal of Community Medicine and Public Health, 5(3), 1060-1063.

- Ssemugabo, C., Wafula, S. T., Ndejjo, R., Oporia, F., Osuret, J., Musoke, D., \& Halage, A. A. (2019). Knowledge and practices of households on safe water chain maintenance in a slum community in Kampala City, Uganda. Environmental Health and Preventive Medicine, 24(1), 1-9.

- World Health Organization. (2017). Guidelines for Drinking Water Quality, incorporating the first addendum. ISBN: 978-92-4-154995-0. Fourth edition. Geneva, Switzerland. World Health Organization publisher, 1.

- World Health Organization. (2015). Unicef /WHO joint press released. Final MDG progress report on water and sanitation released.

Cite This Article: Mawahib Mohammed Salih Ibrahim, Ahmed Sayed Ahmed ElSayed, Fatima Fadul Ali Osman (2022). Effects of a Health Education Program on Water Treatment and Safe Storage, East Nile Locality, Khartoum State. EAS J Nurs Midwifery, 4(1), 8-15. 